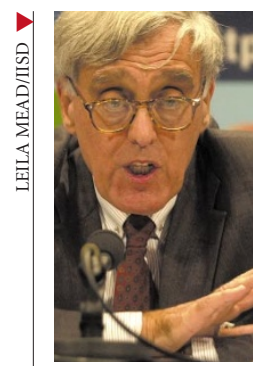

include reforestation efforts in the developing world in its calculations, and had cut its demands for the maximum domestic allowance for carbon sinks from 300 million to 75 million tonnes a year.

This move was US delegate reported by the WashFrank Loy agreed ington Post as having to compromise. followed a late-night conversation between

President Bill Clinton and British Prime Minister Tony Blair, and formed the basis of a compromise agreement thrashed out between Blair's deputy, John Prescott, and the US delegation led by Frank Loy.

But some European countries rejected the agreement. Particularly strong opponents were the environment ministers of France and Germany, Dominique Voynet and Jürgen Trittin, respectively, who are both members of their countries' Green parties. Voynet said that Britain had "conceded too much to America".

Supporters of the US-UK compromise blamed the failure to bridge the negotiating gap on the inability of government officials, exhausted after two weeks of talks and two all-night negotiating sessions, to calculate its technical implications accurately.

Jan Pronk, the Dutch environment minister and chairman of the conference, said that the key political issues including rules for counting emissions from carbon sinks - "could not be resolved in the time available".

Environmental groups oppose any allowance for sinks in emissions calculations. Greenpeace described earlier proposals from Pronk, which would have allowed the United States to include 50 million tonnes of sinks a year in its calculations, as a "free gift" that would allow emissions to continue growing.

But there are signs that the inclusion of sinks could increase the chances of the Kyoto agreement being ratified in the US Senate. US farmers' groups this month came out in favour of an international agreement on carbon sequestration.

"This is a critical shift which greatly improves the chances that the Senate will ratify the Kyoto Protocol," says Philip Clapp, president of the National Environmental Trust, a Washington-based advocacy group.

Margot Wallström, the European Union's environment commissioner, said that the experience of the UN Convention on Biological Diversity, which was agreed only at the second attempt, "shows that a temporary setback can lead to a better result in the end".

\title{
Argentinian researchers fight government plans for reform
}

\section{Xavier Bosch}

Argentinian scientists, already facing financial constraints caused by the country's international debt crisis, are rebelling over the government's plan to reform the National Council for Science and Technology (CONICET).

One of Latin America's most prestigious research agencies, CONICET employs 3,500 of Argentina's best researchers. Earlier this year, the Argentinian cabinet approved a plan by the science and technology ministry to boost links between CONICET and the country's universities.

But senior Argentinian scientists have attacked the plan as financially motivated and detrimental to CONICET's hard-won scientific reputation.

Under the plan, all new members of CONICET would join at the same rank and would receive a $\$ 1,000$ supplement to any university salary. They would compete with each other for university promotions, but if any of the new researchers failed to make the grade after four years, they would lose their CONICET membership.

Evaluation of the researchers' work would be carried out jointly by the universities, CONICET and the National Agency for the Promotion of Science and Technology. The status of current CONICET members would be unchanged by the reforms, although they could opt to join the new system.

The reforms will give more opportunity to young researchers and increase their mobility, says Dante Caputo, secretary of science and technology. He believes that CONICET has become too bureaucratic, and that careers are blocked by its hierarchical structure, which divides researchers into five ranks based on seniority.

In a statement, the directors of some of the agency's research centres admitted that "young people have almost no possibility of entering CONICET". The average age of a CONICET researcher is 50, a problem the directors blamed on low public investment.

Armando Parodi, scientific director of the Biotechnology Research Institute at San Martin University near Buenos Aires, says that CONICET promotions are evaluated seriously and based on academic merit. He says that Caputo's plan would destroy the agency's career structure, and that it was drawn up without consulting researchers.

Parodi adds that the plan is supported by the administrators of the country's big universities, who he believes want to get their hands on CONICET's funds and its influence on academics. He says that the government's argument for better interaction does not stand up, as three-quarters of CONICET researchers already teach in universities.

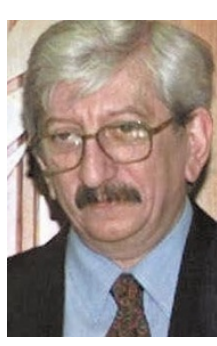

Young scientists will benefit, says Dante Caputo.
José Viramonte, director of CONICET's Geonorte Earth sciences institute in Buenos Aires, says that the plan has been devised by Argentina's "bureaucratic establishment" to extend its power.

"Unlike the universities, CONICET has kept its distance from electoral commitments and cronyism," he says.

\section{German universities used forced labour}

\section{Christina Hohmann, Munich}

Academic institutions in Germany used thousands of forced labourers during the Second World War, according to evidence emerging from some universities and the Max Planck Society.

Victims of the practice, and in some cases their relatives, are eligible for compensation from a DM10 billion (US $\$ 4.3$ billion) fund created last year by German industry and government. But time is hardly on their side: only about 2.4 million of the estimated 11.3 million forced labourers who worked in Germany between 1939 and 1945 are thought to be still alive.

Discussions in the press about largescale forced labour in industry have tended to overshadow the actions of universities, which were also major employers at the time. But some universities have searched their archives for evidence of culpability.

The University of Tübingen, for example, has admitted that it used $\mathbf{1 5 0}$ forced labourers, 120 of whom were eastern European women working in kitchens or as nurses in the university clinic. The men, mostly prisoners of war, worked as handymen or gardeners.

The University of Heidelberg's records from 1944 list 23 'eastern workers', as well as 17 Russian civilians, seven French workers and one Croatian. The University of Stuttgart's list of alien workers and prisoners of war, drawn up in 1946 at the 


\section{NASA U-turns enrage planetary scientists}

\section{William Triplett, Washington}

Planetary scientists in the United States have criticized a string of recent cancellations of missions at NASA, warning that they may put the future health of US planetary exploration at risk.

Following NASA's fourth cancellation of a scheduled planetary science mission in two years, the American Astronomical Society's Division for Planetary Science (DPS) has issued a strongly worded statement arguing that any more cancellations would result in "excessively reduced" programme content and narrow the scope of US space research.

The latest cancellation was the nanorover, a NASA component of Japan's MUSES-C asteroid sample-return mission. That followed the abandonment of the DS4/Champollion comet mission and the Mars 2001 Lander, a follow-up to the Mars Polar Lander that failed in late 1999. In September, NASA stopped work on the Pluto-Kuiper Express mission, scheduled to launch in 2004, that was to study Pluto's atmosphere before exploring the Kuiper Belt.

NASA says the cancelled missions were plagued by cost overruns. But the planetary scientists say NASA could have tackled these by increasing the peer review of proposed missions and making the mission-proposal process an open competition. For decades, the Jet Propulsion Laboratory (JPL) in Pasadena, California, has been in charge of NASA's planetary exploration missions.

Ed Weiler, NASA's head of space science since 1998, who cancelled three of the four missions, says he would like to implement more competition. But Weiler maintains that he must first cope with the problems facing existing missions, which were all instigated by his predecessor, Wes Huntress, currently vice-chairman of the DPS.

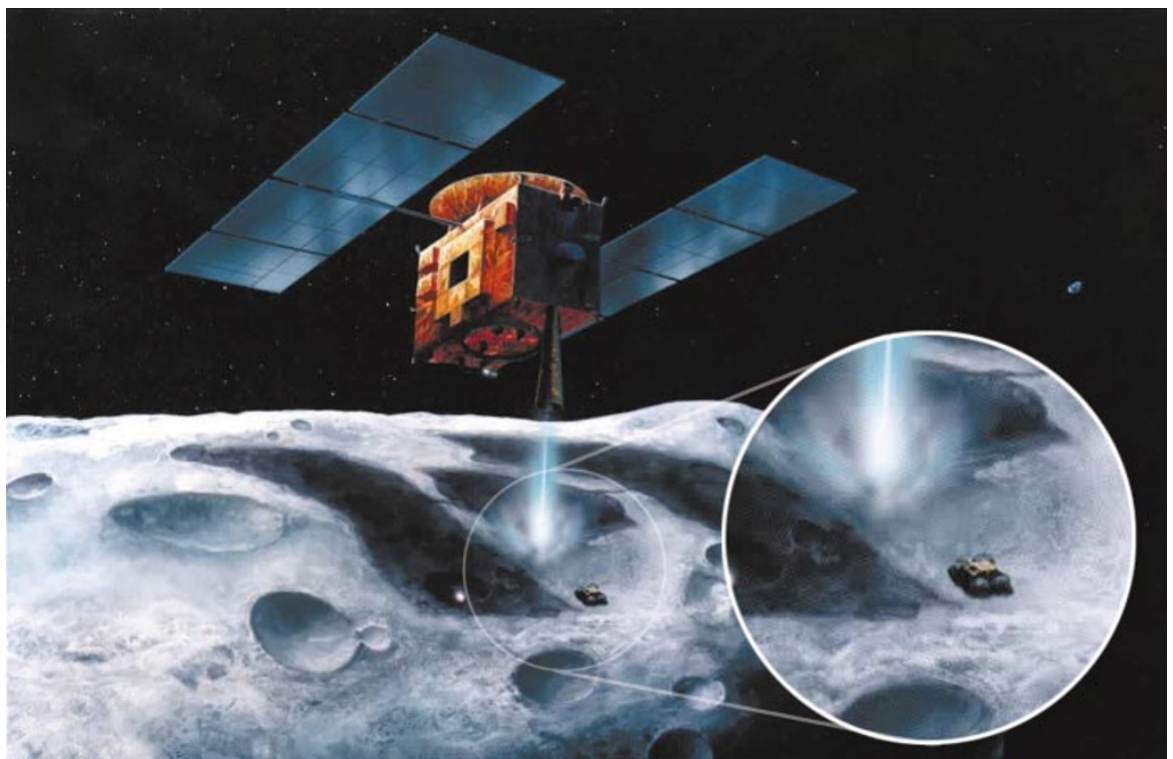

Rover's over: the nanorover (inset) on the MUSES-C asteroid mission is NASA's latest cancellation.

Weiler argues that the cancellations were unavoidable. The nanorover, for example, was priced at around $\$ 20$ million about four years ago, but the latest estimates put its cost at more than $\$ 60$ million. Similarly, the JPL put a figure of $\$ 650$ million on a two-mission package including the Pluto expedition, whereas the latest figures put the price at over $\$ 1.4$ billion.

Michael Drake, who chairs the solar system exploration subcommittee of NASA's Space Science Advisory Committee, says he is "sympathetic to NASA on this because fiscal discipline must be maintained". The space agency has been plagued by unrealistically low bids from contractors, says Drake.

But Mark Sykes, chairman of the DPS, says Weiler's hardline approach risks "throwing the baby out with the bathwater". He fears that the Europa orbiter - a mission to explore one of Jupiter's moons for signs of life - could be next for the chop.

Sykes acknowledges that NASA's plans for exploring Mars are still very much alive, but he does not want Mars to be the only planet studied.

Weiler concurs, but says: "I want to find a way to make these other outer-planet missions cheaper." He says he is considering opening missions up to bids from universities or federally funded institutions. Weiler has told the JPL that the Pluto mission could go ahead if it can cut costs on other projects.

Huntress and his allies would like to see NASA consider alternatives to cancelling missions. "There are lots of ideas out there," he says. "If one mission is running over costs, why not look for other cheaper ideas for the same mission?" request of the local government after the war, contains 56 names.

These lists are almost certainly

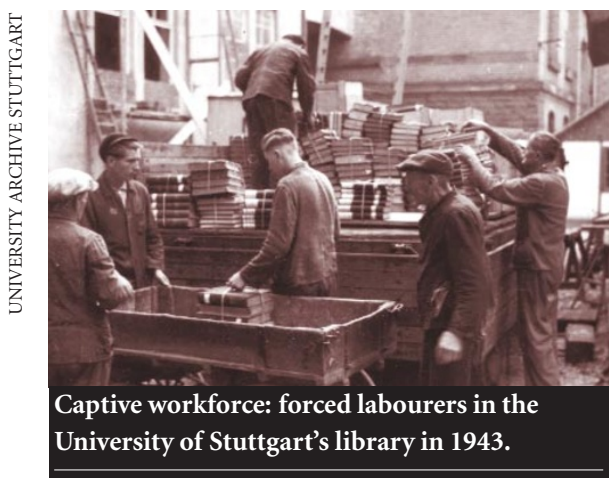

NATURE $\mid$ VOL 408 | 30 NOVEMBER 2000| www.nature.com underestimates of the true number of forced labourers. Dieter Speck, head of the archive of the University of Freiburg, which lists more than a dozen cases there, says that investigations are "very difficult and frustrating", as many records have been destroyed or handed over to the occupying forces. Extrapolating from surviving documents, he estimates that academia as a whole must have exploited several thousand forced labourers.

The Kaiser Wilhelm Society, the predecessor of the Max Planck Society, employed a "large number of forced labourers, maybe up to a thousand individuals", says Jens-Christian Wagner, a historian and member of an independent research group investigating the episode. Its findings will be published next month.

Researchers have found that a class system operated among the forced labourers. Those from the west were often considered capable of being 'Germanized' and received preferential treatment. For example, three French prisoners of war worked at the University of Freiburg in their own professions as librarians and archivists, and remained at the university after the war.

Most universities have taken few steps to contact forced labourers or their relatives. One exception is the University of Tübingen, which some years ago invited 30 former forced labourers from Poland to a reception as a gesture of apology. 